BIOTROPIA No. 11, 1998: 1 - 8

\title{
STUDIES ON NATURAL PRODUCTS OF ALBIZIA SP.
}

\author{
HILMANAFFANDI, ARIFNURYADIN \\ SEAMEO BIOTROP, P.O. Box 116, Bogor 16001, Indonesia \\ and \\ ROGERW.READ \\ Department of Organic Chemistry, The New South Wales University, \\ P.O. Box 1 Kensington, N.S.W. 2033, Australia
}

\begin{abstract}
The bark of Albizia lebeckioides and Albizia falcataria have been examined for their chemical constituents. A. lebeckioides has yielded the steroidal ketone, stigmasta-4,22-dien-3-one, and a triterpene alcohol as the major neutral components. A. falcataria has yielded a similar triterpene and fatty ester as its major constituents. The toxicity of the compounds was evaluated in bioassay against termites.

The results showed that lupenone and stigmastadienone were toxic ioNeotermes dalbergiae species. In contrast these compounds were less toxic to Cryptotermes cynocephalus species.
\end{abstract}

Key words: Insecticidal plants / Albizia lebeckioides I Albizia falcataria I Bark / Extracts / Chemical constituents / Toxicity / Termites

\section{INTRODUCTION}

Some substances are produced by plants reasons for such as defence, growth regulation, hormonal action or as waste products. In teak (Tectona grandis L.f), for example, tectoquinone is produced to protect these trees against termite attack (Romanis 1887; Oshima 1919; Wolcott 1946). Resin ofPinus possesses a number of biologically active natural products. A major constituent, a-pinene is well known for its antimicrobial and insecticidal properties (Bridges 1987).

Among fast growing trees, Albizia falcataria was reported to resist termite attack (Kalshoven 1950; Griffioen 1954). Laboratory tests designed to study the resistance of Albizia falcataria against dry wood termites (Cryptotermes cynocephalus) revealed that the resistance of Albizia falcataria lies somewhere between that of teak and Hevea brasiliensis or even closer to teak (Tarumingkeng and Martawidjaja 1969). Another species of Albizia e.g. Albizia lebeckioides was reported earlier to contain toxic alkaloids (Greshoff 1914).

These reports suggested that both species of Albizia may contain useful chemicals that resist termite attack, therefore a search for biologically active 
compounds from the bark of Albizia falcataria and Albizia lebeckioides was undertaken. The objective of this study was to isolate and characterize the main chemical components and to determine their toxicity to termites.

\section{MATERIALS AND METHODS}

\section{General}

'H NMR spectra were recorded at $500 \mathrm{MHz}$ and ${ }^{13} \mathrm{C}$ NMR spectra were measured at $125.6 \mathrm{MHz}$ on a Bruker AM 500 spectrometer. Mass spectra were recorded at $70 \mathrm{eV}$ with an A.E.I. MS 12 spectrometer. All measurements were performed at the School of Chemistry, the University of New South Wales, Australia.

Initial column chromatographic separations were made on Merck 60 silica gel. Merck Kieselgel 60 F254 was employed for preparative TLC with a $1 \mathrm{~mm}$ layer of adsorbent on $20 \times 20 \mathrm{~cm}$ glass plates and $200 \mathrm{mg}$ of material applied to each plate. Analytical TLC was performed on commercial aluminium-backed Merck Kieselgel 60 $\mathrm{F}_{2} 54$ Art. 5554 plates, visualizing under UV $254 \mathrm{~nm}$ light or charring after applying a 4\% $\mathrm{H}_{2} \mathrm{SO}_{4} / \mathrm{MeOH}$ spray.

\section{Plant Material}

Samples of bark of Albizia falcataria were collected from Kesatuan Pemangkuan Hutan (KPH), Kediri while the bark of A. lebeckioides was taken from Batutulis, Bogor.

\section{Extraction and Isolation}

Dried powdered bark of Albizia lebeckioides $(1.50 \mathrm{~kg})$ was extracted with methanol to give crude extract (78.15 g). The crude extract was then re-extracted with ether to generate an ether soluble fraction (27.77 g) and an insoluble residue (50.37 g). The ether soluble fractions were carefully fractionated by column chromatography (silica gel 60) eluting with hexane containing increasing amounts of ethyl acetate to give 6 fractions. Fraction $4(1.12 \mathrm{~g})$ and fraction 5 (0.98 g), as two major fractions, were subjected to purification by preparative thin-layer chromatography (ethyl acetate hexane, $1: 9$ ). Fraction 4 gave a solid material 
(0.85g) which crystallized from chloroform to give stigmasta-4,22-dien-3-one (2) (0.67 g) m.p. $181-184^{\circ}$. Fraction 5 generated a crystalline solid ( 0.76 g). Recrystallization of the latter gave lupeol (1) (0.51 g) m.p. 198-199.

The bark of $A$. falcataria $(1.50 \mathrm{~kg})$ was treated in a similar manner to the method above. Re-extraction of the crude extract ( $65.83 \mathrm{~g}$ ) with ether gave an ether soluble fraction (16.20 g) and a residue (49.62 g). Fractionation of the ether soluble portion by column chromatography eluting with hexane generated 6 fractions. Purification of the fastest moving fraction $(1.28 \mathrm{~g})$ by preparative thin-layer chromatography (ethyl acetate-hexane, 1:9) gave a solid material (0.93 g) which crystallized from chlorform to give fatty ester (4) (0.82 g). Fraction 2 (1.04 g), upon thin layer chromatography (ethyl acetate-hexane, $1: 9)$ gave a crystalline solid (0.78 g). Recrystallization of the solid from chloroform gave lupenone (3) (0.68 g) m.p. 160-161.

\section{Termite Bioassays}

The toxicity of the pure constituents was evaluated by bioassay using the termite Neotermes dalbergiae, obtained from commercial sources in Bogor, and Cryptotermes cynocephalus, collected from the Forest Product Research Institute, Bogor.

Pure compounds $(25 \mathrm{mg}$ ) were diluted with dichloromethane $(0.5 \mathrm{ml})$. The solutions were applied to $4.5 \mathrm{~cm}$ Whatman no. 1 filter paper dish. After the solvent had been evaporated at ambient temperature, the filter papers were placed in $5 \mathrm{~cm}$ glass petri dishes, and 25 termites added to each container. Control chambers were treated in a similar manner using pure chloroform in place of solutions of the test subtances. Each pure compound was tested in four replicate experiments.

At daily intervals the number of termites surviving was recorded, dead termites were removed, and the filter papers were moistened with distilled water. Dishes were kept covered in a darkened room at ambient temperature.

\section{RESULTS AND DISCUSSION}

\section{Structural Analysis}

Methanolic extracts of the bark of A. lebeckioides and A. falcataria were reextracted with ether. The ether soluble extracts were carefully fractionated by column chromatography (silica gel) and purificed by preparative thin-layer chromatography 
to yield lupeol (1) and stigmata-4, 22-dien-3-one (2) from die bark of A. lebeckioides, and lupenone (3) and fatty ester (4) from the bark ofA.falcataria.

The structure of compound (1) was established from its microanalytical and spectroscopic data. Elemental analysis and mass spectrometry indicated the molecular formula $\mathrm{C}_{0} \mathrm{H}_{50} \mathrm{O}$. The 'H n.m.r. data showed six singlet resonances at 5 0.82, 0.89, 0.93, 0.98, 1.02 and 1.07, arising from six methyl groups attached to quaternary carbons. There also appeared one isolated singlet at 51.68 due to a vinylogous methyl group, and since the olefmic proton signals at 84.56 (dd, J 2.2, 14 Hz) and 4.68 (d J 2.2 Hz) were consistent with a 1,1-disubstituted alkene, a propenyl group was likely. Low field signals resonated at 53.18 (dd, J 10,.9, $5.3 \mathrm{~Hz}$ ), 2.38 (dt, J 5.7, $11.1 \mathrm{~Hz}$ ) and 1.91 (m), but there were no other olefmic resonances. The n.m.r. signal at 83.18 was suggestive of an axial proton adjacent to a quarternary centre and attached to a carbon bearing an hydroxyl group. The ${ }^{\mathrm{I}} \mathrm{C}$ n.m.r. spectrum (Table 1) -supported the structural assignment of (1). In particular there appeared seven methyl signals, only two olefmic carbon signals (8 109.3 (CH2) and 151.0 (C), and a low field methine resonance (8 78.9) for C3. The identity of compound (1) as lupeol was confirmed by melting point and mixed melting point with an authentic sample.

Lupeol has been found in many plant extracts, including the resin of Pistacia leuticus (Marner et al. 1991).

Compound (3) was obviously closely related to lupeol (1). Its mass spectrum gave a molecular ion at $\mathrm{m} / \mathrm{z} 424$, corresponding to two fewer hydrogens than lupeol. The 'H n.m.r. spectrum (Table 2) of compound (3) resembled that of (1), including the appearance of coupled olefmic signals at 84.57 and 4.70, and a deshielded methyl signal due to H3 in lupeol (1) was absent. Instead, there appeared additional signals at 8 2.4, corresponding to protons adjacent to a multiple bond. The compound was thereby identified as lupenone (3) and the structure was confirmed by mixed melting point with an authentic sample.

Compound (2) differed from compounds (1) and (3). Elemental analysis and mass spectrometry indicated through its molecular formula, $\mathrm{C}_{2} 9 \mathrm{H} 4{ }_{6} \mathrm{O}$, that it was a nortriterpene. There appeared in its 'H n.m.r. spectrum two methyl singlets, 8 0.57, 1.01, three methyl doublets, $80.79,0.84,1.03$, and a methyl triplet, 80.80 . Also there appeared a three proton multiplet corresponding to two internally coupled, trans olefmic protons (8 5 03, dd, J 15.1, 8.4 Hz, and 515 (dd, J 15.1, 8.4 Hz) and an isolated olefmic proton (8 5.18, m) with long range coupling, but no other signals at higher chemical shift than $2.5 \mathrm{ppm}$. The presence of a 1,2-disubstituted and a 1,1,2-trisubstituted olefin was supported by the presence of signals at $5117.0(\mathrm{CH}), 129.6$ 
$(\mathrm{CH}), 138.1(\mathrm{CH})$ and $139.5(\mathrm{C})$ in the ${ }^{13} \mathrm{C}$ n.m.r. spectrum. The presence of a quaternary signal at 8212.0 also confirmed the occurrence of a carbonyl group in the compound. Structure (2) was assigned from these data and was confirmed by mass spectrometric fragments at m/z $367\left(\mathrm{M}-\mathrm{C}_{3} \mathrm{H}_{7}\right), 298\left(\mathrm{M}_{-} \mathrm{C}_{8} \mathrm{Hi}_{6}\right), 271(\mathrm{M}-\mathrm{CioH}, 9), 269$ (M$\left.\mathrm{Ci}_{0} \mathrm{H}_{2} \mathrm{i}\right)$, and comparative melting point.

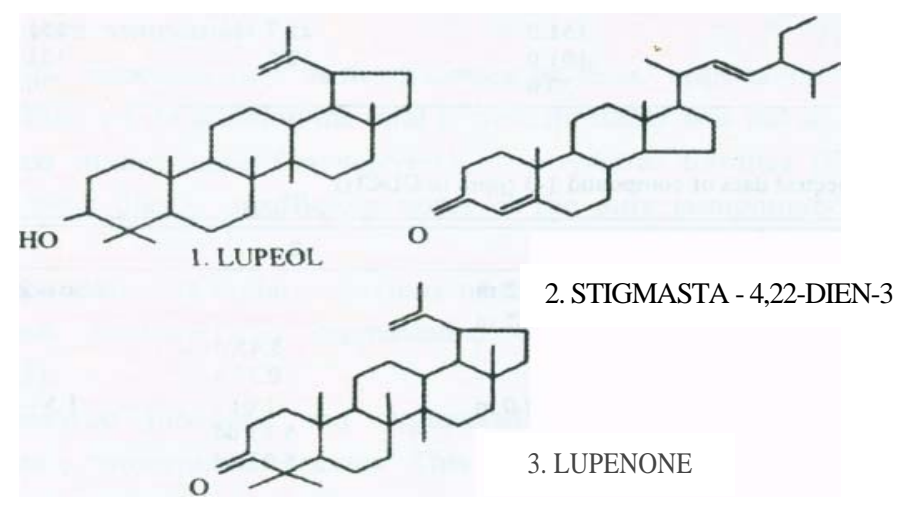

Figure 1. Structures of chemical constituents isolated from the bark of A lebeckioides (1 and 2) and A. falcataria (3)

Table 1. ${ }^{13} \mathrm{C}$ n.m.r. chemical shift data of compounds (1)-(3) (ppm in CDClj)

\begin{tabular}{cccc}
\hline \hline $\mathrm{C}$ & 1 & 2 & 3 \\
\hline 1 & 39.3 & 37.3 & 39.7 \\
2 & 34.3 & 31.6 & 34.1 \\
3 & 55.3 & 212.2 & 218.4 \\
4 & 47.0 & 71.8 & 47.3 \\
5 & 59.3 & 42.3 & 54.9 \\
6 & 19.4 & 121.1 & 19.6 \\
7 & 33.0 & 33.9 & 33.0 \\
8 & 39.9 & 31.7 & 40.3 \\
9 & 50.5 & 50.2 & 50.6 \\
10 & 37.1 & 36.5 & 36.9 \\
11 & 21.8 & 20.9 & 21.9 \\
12 & 26.4 & 38.6 & 26.7 \\
13 & 39.7 & 42.2 & 39.5 \\
14 & 41.2 & 56.6 & 41.0 \\
15 & 26.5 & 24.1 & 26.4 \\
16 & 30.1 & 28.2 & 30.1 \\
17 & 44.7 & 56.1 & 44.9 \\
18 & 37.6 & 11.6 & 37.7 \\
19 & 52.5 & 19.4 & 52.5 \\
20 & 150.6 & 40.8 & 150.8 \\
21 & 30.2 & 21.5 & 30.3 \\
22 & 23.5 & 138.8 & 23.2 \\
\hline
\end{tabular}


Table 1. Continued

\begin{tabular}{|r|r|r|r|}
\hline $\mathrm{C}$ & 1 & 2 & 3 \\
\hline 23 & 26.8 & 129.5 & 26.8 \\
24 & 20.9 & 51.4 & 20.9 \\
25 & 16.2 & 32.2 & 16.3 \\
26 & 15.4 & 19.2 & 15.4 \\
27 & 14.3 & 21.3 & 14.2 \\
28 & 151.0 & 25.7 & 151.1 \\
29 & 101.0 & 12.5 & 101.8 \\
30 & 20.6 & - & 20.7 \\
\hline
\end{tabular}

Table 2. ${ }^{1} \mathrm{H}$ n. m.r spectral data of compound 1-3 (ppm in $\mathrm{CDC1}_{3}$ )

\begin{tabular}{|c|c|c|c|}
\hline $\mathrm{H}$ & 1 & 2 & 3 \\
\hline $\mathrm{H}-2$ & $2.37-2.55 \mathrm{~m}$ & - & $2.36-2.60 \mathrm{~m}$ \\
\hline H-3 & $3.85 \mathrm{~m}$ & - & - \\
\hline H-6 & - & $5.45 \mathrm{~d}$ & - \\
\hline H-18 & - & $0.57 \mathrm{~s}$ & - \\
\hline H-19 & $1.2-2.0 \mathrm{~m}$ & 1.011 & $1.5-2.0 \mathrm{~m}$ \\
\hline H-22 & - & $5.15 \mathrm{dd}$ & - \\
\hline $\mathrm{H}-23$ & $1.07 \mathrm{~s}$ & $5.03 \mathrm{dd}$ & $1.07 \mathrm{~s}$ \\
\hline $\mathrm{H}-24$ & $1.02 \mathrm{~s}$ & - & $1.19 \mathrm{~s}$ \\
\hline H-25 & $0.93 \mathrm{~s}$ & - & $0.94 \mathrm{~s}$ \\
\hline H-26 & $0.98 \mathrm{~s}$ & $0.79 \mathrm{~d}$ & $0.97 \mathrm{~s}$ \\
\hline $\mathrm{H}-27$ & $0.89 \mathrm{~s}$ & $0.84 \mathrm{~d}$ & $0.89 \mathrm{~s}$ \\
\hline H-28 & & $-1.50 \mathrm{~m}$ & - \\
\hline $\mathrm{H}-29$ & 4.56 - dd, $4.68 \mathrm{~d}$ & 0.801 & $4.57 \mathrm{dd}, 4.70 \mathrm{~d}$ \\
\hline
\end{tabular}

Compound (4) could not be obtained pure and its structure could not be fully elucidated. From its 'H n.m.r. spectrum the substance was not terpene derived but was probably a fatty ester. There appeared in the low field region of the spectrum two triplets of equal intensity corresponding to methylene protons adjacent to oxygen $(84.05)$ and a carbonyl group (8 2.28), respectively. In addition, there was a triplet resonance at 8 0.88 that could be assigned to coincident signals from the methyl groups at the ends of aliphatic chains. The remaining signals comprised two narrow multiplets at 81.25 and 8 1.57 corresponding to groups of similar methylene protons. The mass spectrum gave significant ions at $\mathrm{m} / \mathrm{z} 425$ and 205 that could not be assigned to any sensible structure or fragments.

\section{Toxicity of Compounds (l)-(3)}

A laboratory bioassay was conducted to assess the toxicity of pure compounds (l)(3), the tentatively assigned fatty ester (4), and the remaining extracts, to termites. The results showed that $53 \%, 48 \%, 42 \%, 54 \%$, and $64 \%$, respectively, of Neotermes 
dalbergiae termites that were fed these substances remained alive after the fourth day of the experiment (Diagram 1).

While termites in control groups moved actively when the dish was uncovered for counting, temites in treatment groups did not. This observation may suggest that termites receiving chemical treatment responded in a general rather than specific manner to pure compounds.

Specific responses such as death caused by direct application onto the termites were not observed. In addition the total termite mortality was not as high as expected from related studies using Cryptotermes cynocephalus termites (Diagram 2). This may have been due to insufficient doses of the pure compounds rather than low activity.

Comparison of the relative toxicity of the compounds to Neotermes dalbergiae showed that lupenone and stigmastadienone were the most toxic compounds (Diagram I).

In contrast lupenone and stigmastadienone were less toxic against the Cryptotermes cynocephalus species. This might be due to the fact that Neotermes dalbergiae, a drywood termite, does not attack living trees as does the Cryptotermes cynocephalus. Therefore, the former are more susceptible to offensive chemicals, because they have not developed resistance mechanisms (Messer 1990).

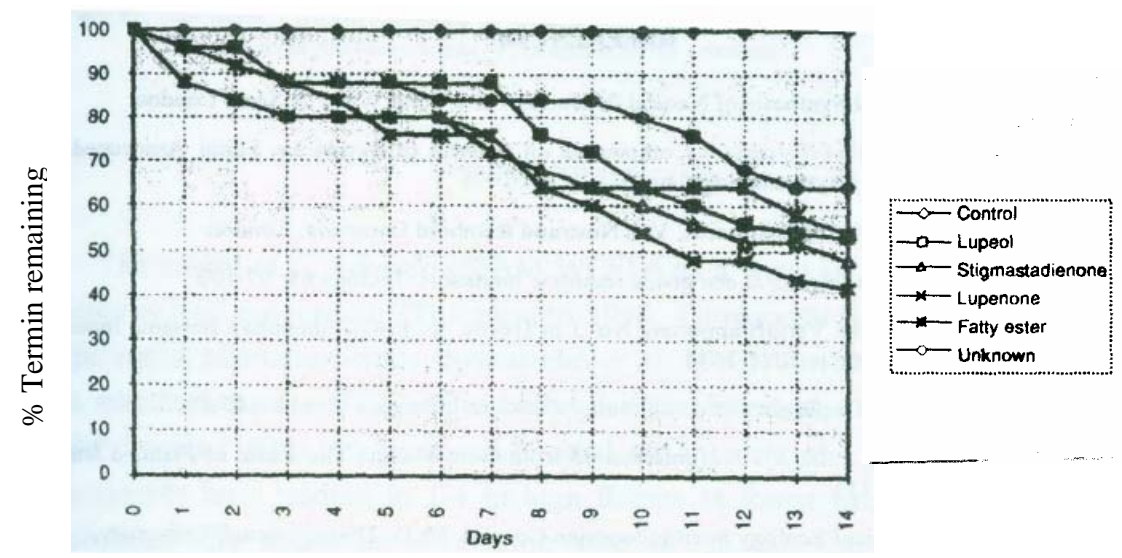

Diagram 1. Toxicity of the compounds against Neotermes dalbergiae 


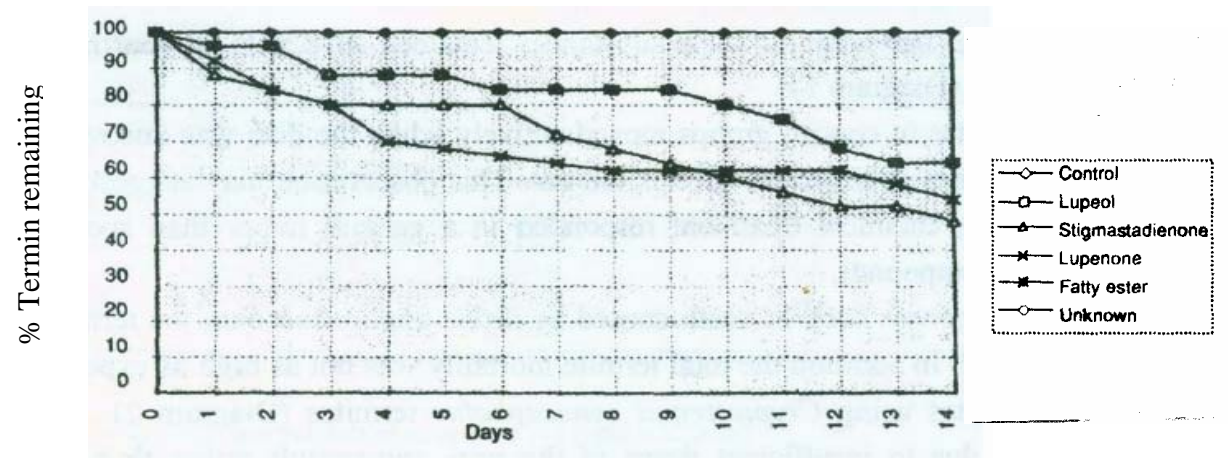

Diagram 2 Toxicity of the compounds againts Cryptotermes cynocephalus

\section{CONCLUSION}

This study has shown that lupenone and stigmastadicnone, contained in the bark of Albizia falcataria and Albizia lebeckioides respectively, have biological activity against the drywood termite Neotermes dalbergiae and that in function they may play a defensive role. Toxic alkaloids, previously reported to be present, (Heyne 1984) have not been found in the bark of Albizia falcataria.

\section{REFERENCES}

APSIMON, J. 1973. The Total Synthesis of Natural Products, Vol 2, John Wiley \& Sons, London.

BRIDGES, J.R. 1987. Effect of Terpenoid Compounds on Growth of Symbiotic Fungi Associated with Southern Pine Beetle. Phytopathology, p. 77.

FffiSER, L.F. AND M. FffiSER. 1959. Steroids, Van Nostrand Reinhold Company, London.

GRIFFIOEN, K. 1964. Albizia falcataria sen goede industrie houtsoort. Tectona 63: 97-100.

GRESHOFF, M. 1914. Indische Vergiftrapporten, No. 3 in Heyne, K. 1987. Tumbuhan Berguna Indonesia, Ruygrok \& Co., Jakarta, p. 1021-1040.

KALSHOVEN, L.C.B. 1950. De plagen van de cultuurgewassen in Indonesia. Deel I: 145-150.

MARKER, F.J., FREYER, A., LEX, J. 1991. Interpenoid from Gum Mastic, The Resin of Pistacia leuticiis. Phytochemistry, 30 (11).

MESSER, A.C. 1990. Chemical Ecology in an Indonesian Context, Ph.D. Thesis, Cornell University. OSHIMA, M. 1919. Formesan Termites and Method of Preventing their Damage. Philip. Sul. 15: 319-386. ROMANIS, R. 1887.

Certain Products from Teak. Chem. Soc. 54: 868.

TARUMINGKENG, R.C. AND A. MARTAWIDJAJA. 1969. Pengujian Kayu Djeundjing (Albizia falcataria Backer) Terhadap Rayap Kayu Kering (Cryptotermes cynocephalus Light) Secara Laboratories. Rimba Indonesia, XIV (1-2)

WOLCOTT, G.N. 1946. What to do about Pollila? Univ. Puerto Rico, Agric. Exp. Sta., Bull. No. 68. 